\title{
Fisiopatologia da doença renal crônica em adultos com doença falciforme
}

\author{
Larissa C. Limaa, ${ }^{1,2,3 *}$ Juliana Omena, ${ }^{1,2}$ Renata Lanziani, ${ }^{1,2}$ Marta Citelli, ${ }^{3}$ Carla Maria Avesani, ${ }^{3,4}$ Claudia dos \\ S. Cople-Rodrigues ${ }^{3}$
}

\section{Resumo}

Doença falciforme(DF) é o termo utilizado para designar alterações genéticas caracterizadas pela presença da hemoglobina $\mathrm{S}$ (HbS). Diferentes genótipos são encontrados nos indivíduos com DF, incluindo a anemia falciforme (HbSS), as associações com variantes de hemoglobinas ( $\mathrm{HbD}, \mathrm{HbC})$ e as interações com talassemias. Uma importante complicação associada à DF é a nefropatia falciforme. O objetivo deste estudo é revisar a fisiopatologia da doença renal crônica (DRC) em adultos com DF. Revisão simples, estruturada em artigos publicados entre 2005 e 2015, utilizando os descritores "doença falciforme", "doença renal crônica" e "nefropatia" nas bases de dados Pubmed/MEDLINE, apenas de estudos realizados em adultos humanos. A vaso-oclusão e a hemólise acentuada causam danos aos tecidos levando à lesão de órgãos, dentre eles os rins. As anormalidades renais observadas, tais como hipostenúria, acidificação deficiente da urina, hematúria e proteinúria, são frequentes, pois a porção medular do rim é uma área particularmente caracterizada por anóxia, hipertonicidade e baixo $\mathrm{pH}$, condições favoráveis à falcização. Embora a fisiopatologia da nefropatia falciforme ocorra mais acentuadamente em indivíduos homozigotos para a $\mathrm{HbS}$, manifestações clínicas da doença renal também são observadas em heterozigotos. Chama a atenção o fato do crescimento da prevalência da DRC estar diretamente relacionada ao aumento da idade e sua repercussão no prognóstico da DF. Os cuidados dos pacientes com DF devem ser adotados desde a infância, uma vez que a DRC e a DF agravam-se com o aumento da idade e o prognóstico da DF é pior na presença da DRC.

Descritores: Anemia falciforme; Insuficiência renal crônica; Nutrição.

\section{Abstract \\ Pathophysiology of chronic kidney disease in adults with sickle cell disease}

Sickle cell disease (SCD) is the term used for genetic disorders characterized by the presence of hemoglobin S (HbS). Different genotypes are found in SCD patients and include sickle cell anemia (HbSS), the HbS associations with other variants of hemoglobin ( $\mathrm{HbD}, \mathrm{HbC}$ ) and interactions with thalassemia. A major complication associated with SCD is sickle cell nephropathy. The objective of this study is to review the pathophysiology of chronic kidney disease (CKD) in adults with SCD. This is a simple review study, structured with articles published between 2005 and 2015, using the keywords "sickle cell disease", "chronic kidney disease" and "nephropathy" in
1. Instituto Nacional de Câncer. Rio de Janeiro, RJ, Brasil.

2. Centro de Referência de Nutrição à Pessoa com Doença Falciforme. Instituto de Nutrição. Universidade do Estado do Rio de Janeiro, Rio de Janeiro, RJ, Brasil.

3. Instituto de Nutrição. Universidade do Estado do Rio de Janeiro, Rio de Janeiro, RJ, Brasil.

4. Programa de Pós-Graduação em Alimentação, Nutrição e Saúde. Instituto de Nutrição. Universidade do Estado do Rio de Janeiro, Rio de Janeiro, RJ, Brasil.

*Endereço para correspondência: Instituto de Nutrição, UERJ.

Rua São Francisco Xavier, 524

Rio de janeiro, RJ, Brasil. CEP: 20559-900

E-mail: larissa_calixto@hotmail.com.

Revista HUPE, Rio de Janeiro, 2015;14(3):58-63

doi: 10.12957/rhupe.2015.19941

Recebido em 19/03/2015. Aprovado em 27/07/2015.

PubMed / MEDLINE databases, using only studies in humans in the adult age. The vaso-occlusive phenomena and severe hemolysis cause tissue damage leading to organ damage, including kidneys. The various types of observed renal abnormalities, such as hyposthenuria, poor acidification of urine, hematuria, proteinuria, are frequent because the medullary portion of the kidney is an area particularly characterized by anoxia, hypertonicity and low $\mathrm{pH}$, which are favorable conditions for sickling. Although the pathophysiology of sickle cell nephropathy occurs more markedly in individuals homozygous for hemoglobin S (HbSS), clinical manifestations of kidney disease are also observed in heterozygous individuals. The increasing prevalence of CKD is directly related to aging and impacts on the prognosis of SCD.The care of patients with SCD should be adopted since childhood, since the CKD and the SCD worsen with increasing age and the prognosis of $\mathrm{SCD}$ is even worse in the presence of CKD.

Keywords: Sickle cell disease; Chronic renal insufficiency; Nutrition.

\section{Resumen}

Fisiopatología de la enfermedad renal crónica en adultos con enfermedad de células falciformes

La enfermedad de células falciformes (ECF) es el término uti- 
lizado para describir las alteraciones genéticas que se caracterizan por la presencia de hemoglobina $\mathrm{S}(\mathrm{HbS})$. Se encuentran diferentes genotipos en los individuos con ECF, incluyendo la anemia de células falciformes (HbSS), las asociaciones con variantes de hemoglobinas $(\mathrm{HbD}, \mathrm{HbC})$ y las interacciones con talasemias. Una importante complicación asociada con la ECF es la nefropatía falciforme. El objetivo de este estudio es revisar la fisiopatología de la enfermedad renal crónica (ERC) en adultos con ECF. Revisión simple, estructurada con artículos publicados entre 2005 y 2015, utilizando las palabras clave "enfermedad de células falciformes", "enfermedad renal crónica" y "nefropatía" en las bases de datos PubMed/ MEDLINE, solamente estudios realizados en humanos adultos. El vaso-oclusión y hemolisis acentuada causan daños en los tejidos, conduciendo a la lesión de órganos, entre éstos los riñones. Las anomalías renales observadas, como hipostenuria,

\section{Introdução}

Doença falciforme (DF) é o termo utilizado para designar as alterações genéticas caracterizadas pela presença da hemoglobina anormal S (HbS), cuja provável origem ocorreu há milhares de anos no continente africano, que afetou uma das bases nitrogenadas do DNA que compõe o gene que sintetiza a globina beta da hemoglobina..$^{1-3}$

Diferentes genótipos são encontrados nos indivíduos com DF, sendo comum a todos as concentrações de HbS superiores a 50\%. ${ }^{2}$ Os indivíduos homozigotos para o gene da hemoglobina S (HbSS) apresentam anemia falciforme (AF) e os heterozigotos apresentam traço falcêmico (HbAS). ${ }^{4}$ Outras anormalidades genéticas associadas à hemoglobina também podem ocorrer em combinação com a HbS, tais como hemoglobina C, hemoglobina $\mathrm{D}$, beta-talassemia, alfa-talassemia, entre outras. As desordens decorrentes da heterozigotia mista em conjunto com a AF são coletivamente chamadas de DF. As formas HbSS (anemia falciforme) e HbS/betatalassemia são as mais graves da DF. ${ }^{1}$

A desoxigenação das moléculas de HbS produzem deformação das hemácias, sendo a mais conhecida a "hemácia em foice" ou "falcizada". Estas hemácias em forma de foice apresentam uma distribuição irregular de imunoglobulinas $\mathrm{G}$ ( $\operatorname{IgG}$ ) em sua superfície, que por sua vez se ligam a receptores específicos das células do endotélio, induzindo à ação fagocitária dos macrófagos no sistema retículo endotelial (SRE).,13 As consequências incluem:(1) enrijecimento e distorção das hemácias, que conduzem a sua destruição prematura; (2) depleção de óxido nítrico; (3) maior ativação à coagulação sanguínea; (4) intensificação das lesões microvasculares. ${ }^{2}$ Essas acidificación urinaria deficiente, hematuria y proteinuria, son frecuentes debido a que la parte medular del riñón es un área particularmente caracterizada por anoxia, hipertonicidad y bajo $\mathrm{PH}$, condiciones favorables para la formación de células falciformes. Aunque la fisiopatología de la nefropatía falciforme ocurre más marcadamente en individuos homocigotos para $\mathrm{HbS}$, las manifestaciones clínicas de la enfermedad renal también se observan en los heterocigotos. Llama la atención el hecho de que la prevalencia de la ERC esté directamente relacionada con el envejecimiento y su impacto en el pronóstico de la ECF. El cuidado de pacientes con ECF debe adoptarse desde la infancia, ya que la ERC y la ECF empeoran con la edad y el pronóstico de la ECF es peor en presencia de la ERC.

Palabras clave: Anemia falciforme; Insuficiencia renal crónica; Nutrición.

modificações têm consequências que as amplificam, levando a manifestações clínicas como anemia profun$\mathrm{da}$, eventos vaso-oclusivos agudos e envolvimento de múltiplos órgãos, incluindo episódios cerebrovasculares, síndrome torácica aguda, retinopatia e nefropatia. ${ }^{1-3}$

A DRC é frequentemente observada em indivíduos com DF, pois a porção medular do rim apresenta condições favoráveis à falcização das hemácias. O aparecimento de anormalidades renais inicia-se na infância e manifesta-se em maior proporção nos indivíduos com anemia falciforme. $2,3,5$

O objetivo deste estudo é revisar a fisiopatologia da doença renal crônica em indivíduos adultos com doença falciforme.

\section{Método}

Estudo de revisão simples, com leitura estruturada de artigos publicados nos últimos 10 anos (2005-2015). Os artigos foram obtidos por meio de estratégia de busca definida, utilizando-se as bases de dados Pubmed/MEDLINE, a partir do cruzamento dos seguintes descritores:

- Estratégia 1 - doença falciforme (sick cell disease) + doença renal crônica (chronic kidney disease)

- Estratégia 2 - doença falciforme (sick cell disease) + nefropatia (nephropathy)

Foram utilizados os termos em inglês para pesquisa nas bases de dados supracitadas. A partir da busca empreendida, os artigos foram escolhidos por sua relevância no campo das ciências da saúde. Conforme definição metodológica do presente artigo, foram selecionados apenas estudos realizados em humanos na faixa etária adulta. 


\section{Artigo de revisão}

\section{Fisiopatologia da doença falciforme: revisão de literatura}

A globina constitui a porção proteica da hemoglobina e é constituída, na vida fetal, por quatro cadeias polipeptídicas, 2 alfa e 2 gama - quimicamente definida como $a_{2} \gamma_{2}$ - sendo chamada hemoglobina $\mathrm{F}$ (HbF). Após o nascimento, ocorrem alterações necessárias para a adaptação às diferentes tensões de oxigênio nos pulmões, e a síntese da hemoglobina F é permanentemente substituída pela síntese da hemoglobina A $(\mathrm{HbA})$, constituída por duas cadeias polipeptídicas alfa e duas cadeias polipeptídicas beta - quimicamente definida como $a_{2} \gamma_{2}$. Cada molécula de HbA é composta por aproximadamente 140 aminoácidos. ${ }^{1,3}$

A fisiopatologia da doença falciforme (DF) é determinada pela substituição da base nitrogenada do códon normal GAG por uma base nitrogenada GTG no gene que codifica a globina da hemoglobina normal (HbA).,3 Como resultado, há uma substituição do sexto aminoácido da globina beta, o ácido glutâmico (classificado como aminoácido de carga negativa), por outro aminoácido diferente, a valina (classificado como aminoácido neutro). A HbA que sofre essa mutação passa a ser denominada $\mathrm{HbS}^{6}$

A desoxigenação da molécula $\mathrm{HbS}$ (oxi-Hb S perde o oxigênio e se torna deoxi-Hb S), processo que ocorre rotineiramente no organismo, permite a formação de pontes de hidrogênio entre o aminoácido valina, normalmente sintetizado para a posição 1 da globina beta $S$, e o aminoácido valina mutante, que substituiu o ácido glutâmico na posição 6 da mesma globina. O resultado é uma modificação na estrutura espacial da HbS que permite a sua ligação a uma molécula adjacente de hemoglobina, provocando a formação de polímeros de filamentos. Estes podem se associar compondo microtúbulos - denominados tactoides - os quais produzem deformação das hemácias. A deformação mais conhecida ocorre quando os feixes de polímeros se organizam paralelamente, dando à hemácia uma forma alongada conhecida por "hemácia em foice" ou "falcizada".,2,7,8

O fenômeno de falcização não é instantâneo, de forma que a hemoglobina pode voltar a se oxigenar e retomar a forma discoide. ${ }^{2}$ Ainda que isso ocorra, a formação de polímeros de HbS dentro das hemácias - mesmo que reversível - leva à falência parcial das bombas de sódio, potássio, cálcio e ATPase. Por conseguinte, a permeabilidade da membrana celular se altera, fornecendo assim uma nova passagem para a perda de água e favorecendo a desidratação eritrocitária.
Com a perda de água, a concentração de hemoglobina (HbS) corpuscular média aumenta, facilitando novas polimerizações da HbS. O estágio final deste processo deletério são hemácias irreversivelmente falcizadas., 3,89

Algumas consequências da falcização incluem: (1) enrijecimento e distorção das hemácias, que conduzem a sua destruição (hemólise) prematura; (2) depleção de óxido nítrico; (3) maior ativação à coagulação sanguínea; (4) intensificação das lesões microvasculares. ${ }^{2,3}$ Essas modificações têm repercussões que as amplificam, levando a manifestações clínicas como anemia profunda, eventos vaso-oclusivos agudos e comprometimento de múltiplos órgãos, como episódios cerebrovasculares, síndrome torácica aguda, retinopatia e nefropatia. ${ }^{8}$

\section{Nefropatia falciforme}

As afecções renais são relativamente frequentes em pacientes com doença falciforme, pois a porção medular do rim é uma área particularmente caracterizada por anóxia, hipertonicidade e baixo $\mathrm{pH}$, condições favoráveis ao fenômeno de falcização. ${ }^{10,11}$ As anormalidade podem estar associadas a alterações estruturais do rim - tanto glomerulares, como tubulares - e a alterações hemodinâmicas e de síntese dos hormônios sintetizados localmente. ${ }^{10}$

A prevalência de nefropatia em indivíduos heterozigotos varia acentuadamente entre os genótipos da doença, e mesmo em indivíduos com o mesmo genótipo, é possível detectar pacientes assintomáticos para esta afecção, enquanto outros apresentam sintomatologia evidente em consequência da anormalidade renal. ${ }^{6}$

\section{Modelo atual da nefropatia falciforme}

Os rins são constituídos por unidades funcionais denominadas néfrons. Estes são formados, em termos gerais, pelos glomérulos - tufo de capilares localizados entre as arteríolas aferente e eferente - onde o ultrafiltrado do plasma é formado; e pelo sistema de túbulos contorcido proximal, alça de Henle, contorcido distal e ducto coletor - responsáveis pelos processos de reabsorção e excreção. Os glomérulos, a maior parte dos túbulos contorcidos proximais e parte dos distais localizam-se na camada mais externa do rim, denominada córtex. A camada mais interna, chamada medula, consiste em arranjos paralelos de alça de Henle e ductos coletores. ${ }^{12,13}$

Fisiologicamente, a região cortical dos rins é irrigada por arteríolas aferentes que se ramificam em capilares que constituem o glomérulo. O sangue continua pelas arteríolas eferentes que dão origem aos capilares peritubulares, responsáveis pela irrigação do sistema de 
túbulos localizados na região cortical, e os vasa recta (ascendente e descendente), sistema diferenciado de capilares responsáveis pela irrigação da região medular dos rins. Os vasa recta, semelhante a outros capilares, são altamente permeáveis aos solutos do sangue, exceto às proteínas plasmáticas.1-14

Em indivíduos com DF, a medula renal consiste em um local altamente suscetível à polimerização da hemoglobina S, em função das baixas concentrações locais de oxigênio, além de hipertonicidade e baixo $\mathrm{pH} .{ }^{3}$ A resultante falcização da hemácia culmina com vaso-oclusão dentro dos vasa recta, com insuficiência de circulação sanguínea, isquemia e enfarte das células tubulares. ${ }^{5}$ O resultado é uma perda quase completa dos vasa recta, sendo os poucos vasos sanguíneos medulares existentes marcadamente dilatados e em configuração de espiral. ${ }^{6}$

A progressão da doença ocorre com a liberação de substâncias vasodilatadoras - notadamente prostaglandina e óxido nítrico - como consequência da isquemia medular. Tais substâncias atuam por meio de mecanismo de feedback com o glomérulo, causando aumento na taxa de filtração glomerular (TFG) que, com o tempo, resulta em glomeruloesclerose, proteinúria e eventual falência renal (Figura 1). ${ }^{6}$

Embora a fisiopatologia da nefropatia falciforme ocorra mais acentuadamente em indivíduos com anemia falciforme e com S-beta talassemia, não se sabe quais os indivíduos com DF desenvolverão DRC.,11,15 Apesar de nem todos os pacientes desenvolverem proteinúria, os relatos em adultos com AF demonstram que o seu desenvolvimento pode progredir para falência dos rins. ${ }^{10,16}$

O estudo realizado por Mendonça com 124 pacientes apresentando anemia falciforme observou o aumento da idade como um importante fator para o desenvolvimento dos sintomas relacionados à DRC, tais como microalbuminúria e proteinúria, cuja frequência foi de $19,4 \%$ e $18,5 \%$, respectivamente, na faixa etária entre 2 e 32 anos. ${ }^{10}$ Níveis elevados desses indicadores correlacionaram-se positivamente com valores aumentados de marcadores de gravidade da $\mathrm{AF}$ ( $\mathrm{LDH}$, reticulócitos, bilirrubina total e indireta). ${ }^{10}$ De forma similar, Guasch e colaboradores, em estudo envolvendo 184 adultos (idade média de 32 anos) com doença falciforme, observaram maior prevalência de proteinúria nos pacientes acima de 40 anos de idade quando comparados aos indivíduos na faixa etária de 18 a 30 anos (40\% versus $20 \%){ }^{17}$

Estima-se que cerca de $40 \%$ dos pacientes com anemia falciforme terão microalbuminúria e entre $20 \%$ e $30 \%$ desenvolverão proteinúria. Destes, aproximadamente a metade progredirá para doença renal terminal, sendo necessário o tratamento dialítico ou o transplante renal, $, 1,1,18$ ambos importantes marcadores de mau prognóstico. A sobrevida média após este estágio da doença é de quatro anos. ${ }^{15,19}$

\section{Manifestações clínicas da nefropatia falciforme}

Dentre as diversas manifestações renais conhecidas associadas à nefropatia falciforme, as principais incluem dificuldade de concentração da urina (hipostenúria), acidificação deficiente da urina, hematúria e proteinúria associada à hiperfiltração glomerular. Tais eventos se iniciam na infância, como resultado da anemia hemolítica crônica, dos eventos veno-oclusivos intraparenquimatosos e do fluxo sanguíneo aumentado..$^{14,20-22}$

A hipostenúria, inabilidade de concentrar a urina sob condições de privação de água, é a anormalidade renal clinicamente mais conhecida na DF e a primeira manifestação de envolvimento dos rins associada à falcização. ${ }^{69}$ Menos comumente ocorre inabilidade de acidificação da urina, sendo o distúrbio caracterizado como uma acidose tubular renal distal incompleta com a ocorrência de hipercloremia e hiperpotassemia. ${ }^{4}$

A hematúria também é uma das manifestações clínicas frequentes associadas à nefropatia falciforme. Estima-se que entre 3\% e 4\% dos pacientes com doença falciforme apresentem ao menos um episódio de hematúria durante a vida. O sangramento é quase sempre autolimitado, podendo variar de microscópico e indolor para visível e doloroso, necessitando, em alguns casos, de transfusão sanguínea. ${ }^{4}$

A proteinúria é a manifestação clínica mais comum, progredindo muitas vezes para níveis tão altos quanto na síndrome nefrótica. Consiste, per se, fator independente na progressão da nefropatia falciforme, envolvendo os seguintes mecanismos: toxicidade mesangial, sobrecarga tubular, toxicidade de proteínas específicas filtradas e indução de moléculas pró-inflamatórias. ${ }^{22}$ Os principais fatores de risco para proteinúria incluem idade avançada e os baixos níveis de hemoglobina. Esta manifestação é descrita em 15\% a $45 \%$ dos pacientes com anemia falciforme, ${ }^{4}$ dados compatíveis com o encontrado por Aleem (2008), ${ }^{21} \mathrm{em}$ um estudo com 53 pacientes com DF, cuja prevalência de proteinúria encontrada foi de $41 \%$.

Desconhecem-se os aspectos nutricionais das pes- 


\section{Artigo de revisão}

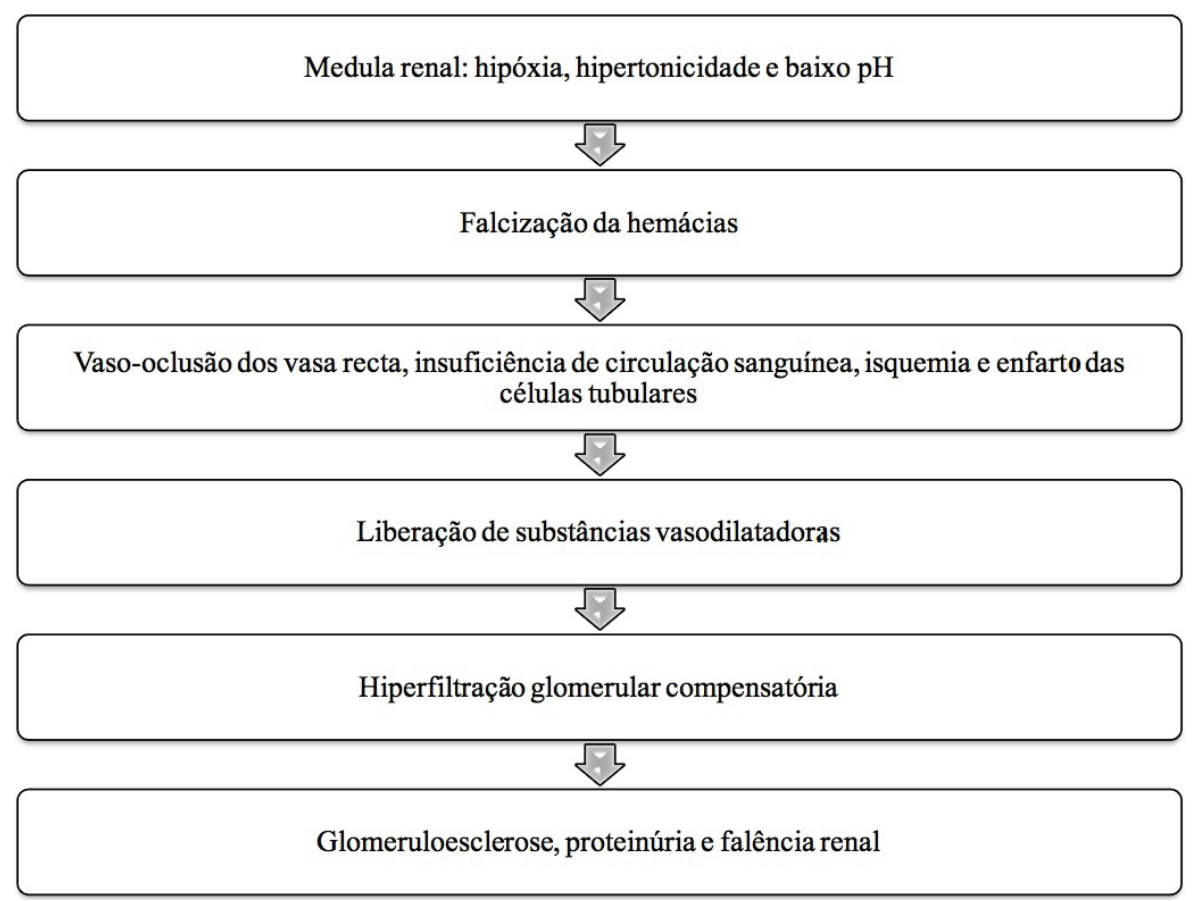

Figura 1. Modelo de desenvolvimento da nefropatia falciforme.

soas com DF que progridem para a DRC, existindo uma grande lacuna a este respeito.

\section{Conclusão}

Os dados levantados nesta revisão indicam que as pessoas com DF apresentam maior propensão ao desenvolvimento de doença renal crônica em função da fisiopatologia da DF. Neste sentido, os cuidados com estes pacientes devem ser adotados desde a infância, uma vez que a DRC e a DF agravam-se com o aumento da idade e o prognóstico da DF é pior na presença da DRC.

\section{Referências}

1. Rees DC, Williams TN, Gladwin MT. Sickle-cell disease. Lancet. 2010; 376(9757):201-31.

2. Zago MA, Pinto ACS. Fisiopatologia das doenças falciformes: da mutação genética à insuficiência de múltiplos órgãos. Rev. Bras. Hematol. Hemoter. 2007;29(3):207-214.

3. Odièvre ME, Verger E, Silva-Pinto AC, et al. Pathophysiological insights in sickle cell disease. Indian J Med Rev. 2011;134(4):532-537.

4. Lei H, Karniadakis GE. Quantifying the Rheological and Hemodynamic Characteristics of Sickle Cell Anemia. Biophys J. 2012;102(2):185-194.

5. Silva Junior GB da, Libório AB.; Daher E de F. New insights on pathophysiology, clinical manifestations, diagnosis, and treatment of sickle cell nephropathy. Ann Hematol. 2011;90(12):1371-1379.

6 . Becker AM. Sickle cell nephropathy: challenging the conven- tional wisdom. Pediatr Nephrol. 2011;26(12):2099-2109.

7. Chirico EN, Pialoux V. Role of Oxidative Stress in the Pathogenesis of Sickle Cell Disease. IUBMB Life. 2012;64(1):72-80.

8. Adekile AD. What's New in the Pathophysiology of Sickle Cell Disease? Med Princ Pract. 2013;22(4):311-312.

9. Magalhães IQ. Alterações renais nas doenças falciformes. Rev. Bras. Hematol. Hemoter. 2007;29(3):279-84.

10. Mendonça ICD. Biomarcadores de lesão na nefropatia falciforme [dissertação]. Sergipe: Universidade Federal de Sergipe, Núcleo de pós-graduação em medicina; 2012.

11. Sharpe CC, Thein SL. Sickle cell nephropathy - a practical approach. 2011;155(3):287-297.

12. Guyton AC. Formação da urina pelos rins: fluxo sanguíneo renal, filtração glomerular e seu controle. In: Guyton AC. Tratado de fisiologia médica. Rio de Janeiro: Guanabara Koogan; 2009. p.248-257.

13. Riella LV, Riella CV, Riella MC. Noções de anatomia e fisiologia renal. In: Riella MC, Martins C. Rio de Janeiro: Guanabara Koogan; 2013. p.3-24.

14. Alhwiesh A. Un update in sickle cell nephrophaty. Saudi J Kidney Dis Transpl. 2014;25(2):249-65.

15. Silva Junior GB, Vieira AP, Couto Bem AX, et al. Proteinuria in adults with sickle-cell disease: the role of hydroxycarbamide (hydroxyurea) as a protective agent. Int $\mathrm{J}$ Clin Pharm. 2014;36(4):766-770.

16. Saraf SL, Zhang $X$, Kanias $T$, et al. Haemoglobinuria is associated with chronic kidney disease and its progression in patients with sickle cell anaemia. Br J Haematol. 2014;164(5):729-739.

17. Guasch A, Navarrete J, Nass K, et al. Glomerular Involvement in Adults with Sickle Cell Hemoglobinopathies: Prevalence and Clinical Correlates of Progressive Renal Failure. J Am Soc 
Larissa C. Lima e cols. • Fisiopatologia da doença renal crônica em adultos com doença falciforme

Nephrol. 2006;17(8):2228-2235.

18. Aneke JC, Adegoke AO, Oyekunle AA, et al. Degrees of Kidney Disease in Nigerian Adults with Sickle-Cell Disease. Med Princ Pract. 2014;23(3):271-274.

19. King L, MooSang M, Miller M, et al. Prevalence and predictors of microalbuminuria in Jamaican children with sickle cell disease. Arch Dis Child. 2011;96(12):1135-1139.

20. Audard V, Moutereau S, Vandemelebrouck G, et al. First evi- dence of subclinical renal tubular injury during sickle-cell crisis. Orphanet J Rare Dis. 2014; 9(67):1-4.

21. Aleem A. Renal Abnormalities in Patients with Sickle Cell Disease: A Single Center Report from Saudi Arabia. Saudi J Kidney Dis Transpl. 2008;19(2):194-199.

22. Emokpae MA, Uadia PO. Sickle Cell Disease and Renal Disease. In: Sahay M. Diseases of Renal Parenchyma. Croácia: InTech; 2012. p.113-134. 